\title{
Editorial
}

Digestion

\section{Quality and Quantity of Life with Pancreatic Cancer}

\author{
Judith S. Jacobson \\ Department of Epidemiology, Mailman School of Public Health, Columbia University, New York, N.Y., USA
}

In the early days of oncology, about half a century ago, most cancer patients were diagnosed with late-stage disease and had poor prospects for survival. Their circumstances justified trials of highly toxic agents. Over the next few decades, clinical trial methodology evolved, and research began to achieve some successes. Today, effective treatment, not necessarily cure but significant prolongation of survival, is widely available for many common cancers. In addition, effective screening methods have been developed for several common cancers and cancer precursors, and for some cancers, early detection does indeed make curative treatment possible.

According to the theory of the hierarchy of needs by Maslow [1], once our immediate requirements for survival are addressed, we turn our attention to quality of life. Thus, as the numbers of long-term cancer survivors grew, cancer clinicians and investigators increasingly acknowledged a responsibility to minimize the adverse effects of treatment and the disease on quality of life.

Cancer of the pancreas has largely been left out of the cancer research success story. Five-year survival among patients with pancreatic cancer is about $5 \%$, and median survival is less than 1 year. Even among patients diagnosed with localized disease, 5-year survival is less than $20 \%$. However, patients with pancreatic cancer are beginning to benefit from the growing concern of clinical cancer investigators for quality of life. Assessment of quality of life is a routine feature of pancreatic cancer clinical trials, although its purpose may be merely to find some difference between treatment arms in the absence of a difference in survival or extent of disease [2-4].

\section{KARGER}

Fax +4161306 1234

E-Mail karger@karger.ch

www.karger.com (c) 2006 S. Karger AG, Basel

0012-2823/06/0742-0116\$23.50/0

Accessible online at:

www.karger.com/dig
In this issue, Müller-Nordhorn et al. [5] report on health-related quality of life among pancreatic cancer patients using both the questionnaire of the European Organization for Research and Treatment of Cancer (EORTC), which assesses function and symptoms, and the EuroQoL (EQ-5D) questionnaire, which assesses utilities with reference to national norms. In this analysis, two sets of norms were used: German norms from a sample approximately matched for age with the German patients participating in the study, and English norms, which are most often used in the literature.

It is no surprise that the 45 consecutively recruited patients with a confirmed diagnosis of pancreatic cancer, including 20 with metastatic disease, reported impaired functioning, worse symptoms and problems, and poorer quality of life than the norm populations (exceptions were cognitive functioning and pain scales in women). The value of the study lies in its analysis of symptoms and functional areas as predictors of healthrelated quality of life. In a linear regression model adjusted for age and sex, the only statistically significant predictors of impaired quality of life were fatigue and pain, in that order.

Pancreatic cancer has been shown in several studies to be associated with depression and anxiety [6-8]. In the EORTC functional scales, patients scored especially poorly on emotional and social functioning, presumably due to anxiety and depression. Whether those states are the cause or result of fatigue, pain and poor prognosis among patients with the disease or are related to disease processes remains to be determined.
Judith S. Jacobson, DrPH, MBA

Department of Epidemiology, Mailman School of Public Health, Columbia University 722 West 168th Street, R736

New York, NY 10032 (USA)

Tel. +1 212305 2502, Fax +1 212305 9413, E-Mail jsj4@columbia.edu 
Recently, studies have found that gemcitabine-based chemotherapy regimens have some survival benefit for patients with pancreatic cancer [9]. A new generation of chemotherapeutic agents may extend these benefits [10]. However, it is scarcely a service to prolong the existence of a patient who is in too much pain or too exhausted and depressed to go to work or to enjoy being with friends and family. So determining what symptoms and concerns are most burdensome to pancreatic cancer patients is important. Of course, survey findings are no substitute for asking individual patients about their symptoms and concerns.

Müller-Nordhorn et al. [5] urge the development of interventions to improve symptom control and to allevi- ate psychological distress for patients with pancreatic cancer. In the absence of effective treatments for the disease, they suggest that learning how to keep patients comfortable is the least we can do.

The provision of supportive care from the time of diagnosis to the end of life is increasingly acknowledged as a responsibility of clinicians and clinical investigators. Addressing symptoms and side effects may not only enhance comfort but improve attitudes toward treatment, promote treatment adherence and prolong survival. And, if psychological distress in the context of pancreatic cancer is linked to the biology of the disease, studying it may lead to the identification of disease mechanisms that can be targets for new therapies.

\section{References}

1 Maslow A: A theory of human motivation. Psychol Rev 1943;50:370-396.

2 Burris H, Storniolo AM: Assessing clinical benefit in the treatment of pancreas cancer: gemcitabine compared to 5-fluorouracil. Eur J Cancer 1997;33(suppl 1):S18-S22.

3 El-Kamar FG, Grossbard ML, Kozuch PS: Metastatic pancreatic cancer: emerging strategies in chemotherapy and palliative care. Oncologist 2003;8:18-34.

4 Glimelius B, Hoffman K, Sjoden PO, Jacobsson G, Sellstrom H, Enander LK, et al: Chemotherapy improves survival and quality of life in advanced pancreatic and biliary cancer. Ann Oncol 1996;7:593-600.
5 Müller-Nordhorn J, Roll S, Böhmig M, Nocon M, Reich A, Braun C, Noesselt L, Wiedenmann $\mathrm{B}$, Willich $\mathrm{SN}$, Brüggenjürgen $\mathrm{B}$ : Health-related quality of life in patients with pancreatic cancer. Digestion 2006;74:118125.

6 Kelsen DP, Portenoy RK, Thaler HT, Niedzwiecki D, Passik SD, Tao Y, et al: Pain and depression in patients with newly diagnosed pancreas cancer. J Clin Oncol 1995;13:748755.

7 Carney CP, Jones L, Woolson RF, Noyes R Jr, Doebbeling BN: Relationship between depression and pancreatic cancer in the general population. Psychosom Med 2003;65: 884-888.
8 Zabora J, BrintzenhofeSzoc K, Curbow B, Hooker C, Piantadosi S: The prevalence of psychological distress by cancer site. Psychooncology 2001;10:19-28.

9 Burris HA 3rd, Moore MJ, Andersen J, Green MR, Rothenberg ML, Modiano MR, et al: Improvements in survival and clinical benefit with gemcitabine as first-line therapy for patients with advanced pancreas cancer: a randomized trial. J Clin Oncol 1997;15: 2403-2413.

10 Burris HA 3rd: Recent updates on the role of chemotherapy in pancreatic cancer. Semin Oncol 2005;32(suppl 6):S1-S3. 